\title{
O que ensinam liuros didáticos de Artes do Ensino Médio sobre arte dos pouos indígenas
}

\author{
What Art High School textbooks teach about Indigenous art
}

\section{Lo que enseñan libros didácticos de Artes de la enseñanza media sobre arte de los pueblos indígenas}

Mariana Schnorr Thomas'

Colégio Ulbra São Lucas, Professora de Artes

\section{lara Tatiana Bonin ${ }^{2}$}

Universidade Luterana do Brasil, Professora e Coordenadora do Programa de Pós-Graduação em Educação

Resumo: Este artigo discute formas de representação das práticas artísticas dos povos indígenas em dois livros didáticos de Arte para o ensino médio, selecionados para distribuição em escolas públicas por meio do Programa Nacional do Livro Didático de 2015. Sob a perspectiva teórica dos Estudos Culturais em Educação, que orienta o presente estudo, livros didáticos são vistos como artefatos que constituem e propagam conhecimentos e também promovem uma regulação na cultura, à medida que incluem ou excluem aspectos e práticas, nesse caso, dos povos indigenas. A análise mostra que arte indígena é um conceito em disputa, sendo flexionada ora por concepções eurocêntricas, ora por discursos multiculturalistas, quando integrada aos livros didáticos.

Palavras-chave: Arte indígena. Livro didático. Ensino de Arte.

Abstract: This paper discusses ways of representing Indigenous art practices in two art High School textbooks, selected for distribution in public schools through the 2015 Programa Nacional do Livro Didático. From the perspective of Cultural Studies in Education, which guides the current study, textbooks are seen as artefacts shaping and spreading knowledge and promoting regulation in culture, while including or excluding, in this case Indigenous, aspects and practices. The analysis shows that the Indigenous art is a disputed concept, either bent by Eurocentric conceptions, or multiculturalist discourses, when it is included in textbooks.

Keywords: Indigenous art. Textbooks. Arts teaching.

Mestre em Educação pela Universidade Luterana do Brasil; Licenciada em Artes Visuais pela Universidade Luterana do Brasil; https://orcid.org/0000-0002-3634-5807; http://lattes.cnpq.br/2410699424299625.

2 Doutora em Educação pela Universidade Federal do Rio Grande do Sul; Mestre em Educação pela Universidade de Brasilia; https://orcid.org/0000-0001-7156-8849; http://lattes.cnpq.br/7925856179663459. 
Resumen: Este artículo discute formas de representación de las prácticas artísticas de los pueblos indígenas en dos libros didácticos de Arte para la enseñanza media, seleccionados para distribución en escuelas públicas a través del Programa Nacional do Livro Didático de 2015. Bajo la perspectiva teórica de los Estudios Culturales en Educación, que sostiene al presente estudio, libros didácticos son vistos como artefactos que constituyen y propagan conocimientos y también promueven una regulación en la cultura, incluyendo o excluyendo aspectos y prácticas, en este caso, de los pueblos indígenas. El análisis muestra que el arte indígena es un concepto en disputa, siendo flexionada por concepciones eurocéntricas, ora por discursos multiculturalistas, cuando se integra a los libros didácticos.

Palabras clave: Arte indígena. Libro didáctico. Enseñanza de Arte.

Recebido em 20 de maio de 2018

Aceito em 17 de janeiro de 2019

Publicado em 20 de fevereiro de 2019

\section{PALAURAS INICIAIS}

Na cena pedagógica contemporânea os discursos em prol das diferenças adquirem relevância, mobilizados, por um lado, pela dissolução de ideais de homogeneização cultural e de fixação de determinadas identidades referenciais e, por outro lado, por processos de globalização intensificados nas últimas décadas, que ampliaram sensivelmente o trânsito de pessoas, de produtos, de mensagens, de tecnologias. Dentro desse panorama mais geral, a "diferença" adquire notoriedade e passa a figurar mais explicitamente em produções culturais da atualidade, o que amplia também as possibilidades de abordagem em materiais que circulam nas escolas.

Em parte, isso se deve à ação política de movimentos sociais lindígenas e indigenistas) e às suas reivindicações específicas, voltadas para uma radical transformação nas formas de nomear, caracterizar, representar e posicionar socialmente os povos indígenas em livros didáticos, livros de literatura, animações, filmes, programas de TV, peças publicitárias, entre outros artefatos. No que concerne aos currículos escolares, uma intensa disputa se trava, marcada por novas exigências legais - a exemplo da Lei n. 11.645/2008, que altera a Lei de Diretrizes e Bases da Educação Nacional (Lei n. 9.394/1996), de modo a contemplar uma antiga reivindicação dos movimentos negros e indígenas. 0 texto da LDB passa a vigorar com o seguinte teor:

Art. 26-A. Nos estabelecimentos de ensino fundamental e de ensino médio, públicos e privados, torna-se obrigatório o estudo da história e cultura 
afro-brasileira e indígena. $\S 1^{\circ} 0$ conteúdo programático a que se refere este artigo incluirá diversos aspectos da história e da cultura que caracterizam a formação da população brasileira, a partir desses dois grupos étnicos, tais como o estudo da história da África e dos africanos, a luta dos negros e dos povos indigenas no Brasil, a cultura negra e indígena brasileira e $\circ$ negro e o índio na formação da sociedade nacional, resgatando as suas contribuições nas áreas social, econômica e política, pertinentes à história do Brasil. $\S 2^{\circ}$ Os conteúdos referentes à história e cultura afro-brasileira e dos povos indigenas brasileiros serão ministrados no âmbito de todo - currículo escolar, em especial nas áreas de educação artística e de literatura e história brasileiras." (BRASIL, 2008).

A promulgação dessa Lei produz importantes efeitos, tanto nas propostas curriculares quanto na produção de materiais didáticos - em especial para as áreas textualmente referidas (Arte, Literatura, História). Podemos observar uma mudança sutil também nos currículos dos cursos de licenciatura, conduzidos por diferentes instituições de ensino superior no País. Em algumas delas, conforme Silva (2015), vem sendo incluída uma cadeira nomeada por "Educação Indígena" de modo a contemplar a exigência legal, mas o autor argumenta que não se trata de educação indígena lalgo que concerne às práticas educativas dos povos indígenas), senão de ensino da temática indígena.

Com relação aos artefatos escolares, a Lei n. 11.645/2008 impacta diretamente os critérios de seleção de obras didáticas, especialmente aquelas que são selecionadas para distribuição para escolas brasileiras, com uso de recursos públicos. Mas é preciso reconhecer que a abordagem da história, cultura, arte indígena, por si só, não garante que se ampliarão os espaços de discussão sobre os atuais problemas vivenciados por esses povos, tampouco assegura uma abordagem qualificada, especialmente porque, sem uma formação docente condizente com a atual demanda e sem que se expandam as redes de informação nas quais se produzem e se divulgam as histórias, culturas, nas artes indígenas possivelmente serão mantidas as perspectivas eurocêntricas e pontos de vista estereotipados que permeiam discursos escolares.

Considerando que é central promovermos uma transformação nos modos de pensar e dar sentido às coisas e aos sujeitos que nos rodeiam, neste artigo são analisadas representações das práticas artísticas dos povos indígenas em dois livros didáticos de Arte do ensino médio: Por toda Parte, dos autores Pascoal Ferrari, Solange Utuari, Daniela Libâneo e Fábio Sardo, publicado em 2013 pela editora FTD e Arte em Interação, escrito por Hugo Luiz Barbosa Bozzano, Perla Frenda e Tatiane Cristina Gusmão, publicado pela editora paulista IBEP no ano de 2013.

0 principal critério de escolha dos dois livros mencionados foi sua ampla distribuição em escolas públicas de ensino médio, feita com recursos do Fundo Nacional de Desenvolvimento da Educação (FNDE), pois ambos foram selecionados por meio do Programa 
Nacional do Livro Didático (PNLD) ${ }^{3}$ no ano 2015. Vale ressaltar que este foi o primeiro Edital do PNLD a contemplar o ensino de Arte, sendo os referidos livros aprovados e distribuidos nos anos 2016 e 2017 para as escolas públicas brasileiras, respeitando-se a escolha de cada instituição sobre qual (entre os dois livros) seria adotado.

Sob a perspectiva teórica dos Estudos Culturais em Educação, que orienta este estudo, livros didáticos são vistos como artefatos que constituem e propagam conhecimentos e também promovem uma regulação na cultura, à medida que incluem ou excluem tópicos de conteúdo e, desse modo, estabelecem o que seria adequado ensinar e aprender. Os livros didáticos integram e colaboram para conformar propostas curriculares, e por isso se justifica uma detida análise das representações que neles se constituem e se propagam.

Conforme salienta Paraíso (2010, p. 588), o currículo "é um território de multiplicidades de todos os tipos, de disseminação de saberes diversos, de encontros 'variados', de composições 'caóticas', de disseminaç̃̃es 'perigosas', de contágios 'incontroláveis', de acontecimentos insuspeitados.'" Os currículos relativos ao ensino de Arte também são múltiplos e neles se expressam entendimentos (em disputa, nunca definitivamente estabelecidos) sobre o que integraria efetivamente o artístico - "povoado" por um conjunto seleto de práticas tomadas como relevantes, centrais, indispensáveis para o desenvolvimento do senso artístico e estético nas novas gerações.

Currículos disseminam saberes, constituem pontos de vista sobre as expressões culturais de grupos sociais distintos, produzem seleções interessadas do que, sob determinado prisma, conta como a (verdadeira) arte que deve ser ensinada nas escolas. Concordamos com Santomé (2009) quando afirma que algumas culturas são silenciadas nos currículos, pois os currículos são constituidos a partir de relaç̃̃es de poder que definem $\circ$ que é considerado socialmente relevante para integrá-los. Assim, quando se rompe o silenciamento e se estabelece a necessária inserção das artes indígenas nos currículos, também se busca circunscrever e definir as regas do dizer e do pensar, do transitar e do encontrar (não é qualquer arte, nem qualquer prática que se inscreve, então, como elemento artístico).

Como afirma Silva (2009), as narrativas contidas no currículo - em textos e imagens - validam os conhecimentos que se deseja propagar, definem quais formas de conhecer e 
de se expressar têm prioridade, estabelecem o que é belo e o que é feio, e, poderíamos acrescentar, colaboram para o reconhecimento, por parte dos sujeitos, do que é/o que não é arte, do que seria integrante de "nosso" senso artístico (com o qual nos identificamos, discursos dos quais nos tornamos sujeitos), e o que seria o senso artístico dos "outros". “Por isso, o currículo é muito mais que uma questão cognitiva, é muito mais que construção do conhecimento, no sentido psicológico. 0 currículo é a construção de nós mesmos como sujeitos." (SILVA, 2009, p. 196).

Discorrendo sobre conhecimento escolar e currículo, Moreira e Candau (2007, p. 23) argumentam que

ao observarmos com cuidado os livros didáticos, podemos verificar que eles não costumam incluir, entre os conteúdos selecionados, os debates, as discordâncias, os processos de revisão e de questionamento que marcam os conhecimentos e os saberes em muitos de seus contextos originais.

Nesse sentido, vale a pena indagar em que medida os livros didáticos de arte, selecionados para este estudo, incorporam práticas plurais dos povos indígenas, ainda que as formas de expressão e seus sentidos de arte, no contexto cultural de cada etnia, confrontem ou contrastem com aqueles que orientam, de modo geral, o pensamento sobre o que seja lou não) arte no mundo ocidental contemporâneo.

São abundantes os estudos acadêmicos, feitos há décadas, especialmente nos campos da Antropologia e da Educação, que focalizam as formas de representação da vida e das culturas indígenas em livros didáticos - Costa (1994), Oliveira (2001), Paes (2008), Bonin e Gomes (2008), Aguiar (2011) e Bonin (2010) são autores que vêm se ocupando desse tema e têm demostrado como se propaga uma visão genérica da vida indígena, alicerçada em versões eurocêntricas que operam a conversão de ricas e complexas culturas em meros adendos ou estranhos contrapontos a uma cultura modelar. Silva (2015) afirma que um dos mais importantes desafios, ao abordar a temática indígena na escola, é escapar às imagens exóticas e folclorizadas que se constituem em textos didáticos, literários, midiáticos. Para o autor, uma das concepções mais arraigadas ao pensamento pedagógico sobre os índios no Brasil é a noção de que eles supostamente possuem relações intrínsecas com a floresta, o campo, o mundo rural. Contudo, os dados estatísticos do Censo (IBGE, 2010) afirmam a existência de cerca de $40 \%$ dos índios vivendo em espaços urbanizados - seja porque migraram para cidades de pequeno, médio e grande portes por razões pessoais, seja porque as cidades avançaram sobre seus territórios - dado que confronta a visão mais generalizada de índios vivendo reclusos em ambientes rurais. 
Acrescentaríamos, como um outro importante desafio, o de produzir disposição política (em gestores, professores, alunos, autores de obras didáticas, editores) para conhecer, para além de poucos traços simplificados, as singularidades desses mais de 340 povos indígenas que vivem em condições socioculturais bastante diversas na atualidade brasileira e que utilizam cerca de 240 línguas diferentes para a comunicação (BONIN; RIPOLL; AGUIAR, 2015).

Problematizar representações sobre os povos indígenas propagadas e naturalizadas em discursos didáticos é uma das preocupações de pesquisadores atentos a essa temática, que muitas vezes tomam livros didáticos como artefatos para análise por serem eles os mais comuns nas salas de aula, além de representarem um tipo de saber especializado, validado por instâncias governamentais e, no caso dos que estão sendo analisados neste estudo, com edições financiadas com recursos públicos para distribuição em escolas das redes municipais e estaduais.

\section{LIUROS DIDÁTICOS: ARTEFATOS ÚTEIS PARA A ANÁLISE DE DISCURSOS ESCOLARES}

A produção e distribuição de livros didáticos se consolida, no Brasil, ao longo do século XX e hoje dispõe de larga tradição, bem como de alentado número de estudos e pesquisas acadêmicas, voltados tanto para aspectos históricos quanto para as transformações nos modos de produção, circulação e consumo desses materiais. Contudo, para o ensino de Arte não tem sido comum a produção de livros didáticos, e tal inciativa tem gerado intensos debates.

Por um lado, afirma-se a necessidade de sistematização de conhecimentos sobre as artes que deveriam ser trabalhados na educação básica, salienta-se a urgência em promover ajustes ao que se define como conteúdo mínimo para o componente curricular Arte, em normativas oficiais, e, ainda, destaca-se a necessidade de produção de materiais que possam estimular o interesse pelo que chamamos artístico. Por outro lado, contestase a premissa de padronização do ensino de Arte ou a seleção prévia de determinados conhecimentos, uma vez que existem diretrizes para essa disciplina e a publicação de livros didáticos poderia restringir o potencial de criação e de invenção, nesse campo disciplinar.

No Brasil, o edital do PNLD de 2015 lque previa a seleção de obras para o ensino médio) incluiu, pela primeira vez, o componente curricular Arte, conforme já afirmamos. 0 referido edital convocou editores a inscreverem obras didáticas para o ensino de Arte, desde que estas fossem organizadas em volumes únicos, com uma proposta pedagógica integrada e progressão didática articulada ao currículo dos três anos do ensino médio. Sobre a temática 
indígena, o Edital salientava a observância de princípios éticos na sua abordagem, como forma de contribuir para a construção da cidadania e de bases solidárias para o convívio social. Vedava-se, explicitamente, a presença de estereótipos ou preconceitos ligados a questões socioeconômicas, regionais, étnico-raciais, de gênero, de orientação sexual, idade, linguagem. Tais aspectos seriam avaliados, ao longo do processo de seleção das obras, tanto no que concerne aos textos verbais quanto no tocante às ilustrações, figuras, gráficos e outros elementos visuais (FUNDO NACIONAL DE DESENVOLVIMENTO DA EDUCAÇÃO, 2015).

Sobre a escolha das obras por parte das escolas, o edital previa que elas deveriam firmar, inicialmente, o Termo de Adesão ao Programa (respeitando o indicado na Resolução CD/FNDE n. 42, de 28 de agosto de 2012). Por meio deste e de outros procedimentos, obras didáticas aprovadas no PNLD de 2015 puderam ser indicadas pelas escolas participantes, e essa escolha deveriam envolver corpo docente e gestores. No caso do componente curricular Arte, as duas obras (Por Toda parte e Arte em Interação) foram aprovadas em 2015, e, feita a escolha por parte da escola, o Ministério da Educação distribuiu um número de exemplares correspondente ao de alunos matriculados.

Quanto à estruturação dos livros didáticos de Arte que discutimos neste artigo, observamos que Por toda Parte possui, ao todo, 304 páginas e tem o texto organizado em seis capítulos, ${ }^{4}$ divididos em temas. Cada capítulo contém seções fixas assim intituladas: "Detalhes", "Giro de ldeais", "Projeto Experimental”, “Conexões”, “Conversa com algum artista”, "Resgatando o que você aprendeu" e "Expedição cultural" nas páginas finais do exemplar do professor. № exemplar do docente apresenta-se uma seção chamada "Diálogo com o Professor", contendo १२ páginas, que assume a forma de manual didático. Já a obra Arte em Interação possui 400 páginas, sendo acrescentadas, na versão para o professor, mais 104 relativas ao manual didático. São nove capítulos, ${ }^{5}$ e neles são encontradas as seguintes seções fixas: "Abra a janela", "Foco na prática", "Tantas histórias", "Cápsulas", "Conexão", “Enquanto isso..." e "ldeias em fluxo". Tomando, então, os dois livros selecionados para distribuição nas escolas públicas de ensino médio como material empírico, propomos neste artigo uma discussão sobre as formas de inserção da arte indígena nos textos didáticos.

4 Os capítulos são assim intitulados: "0 que é arte?", "Por línguas e línguas", “A criação", "Matérias da arte”, "A arte em sua forma, a forma em seu conteúdo" e "Bagagem cultural".

5 Os títulos dos capítulos são os seguintes: "Imaginação e Expressão", "Identidade e Diversidade", “Arte e Vida", "Rupturas", "Linguagens do corpo", "Conflitos Humanos", "Ser humano, ser político", "Canibalismo Cultural" e "Tecnologia e Transformação Cultural". 


\section{APONTAMENTOS SOBRE AS NORMATIUAS QUE REGULAM 0 ENSINO DE ARTE}

Especificamente sobre o ensino do componente curricular Arte, consideramos oportuno retomar alguns aspectos legais para traçarmos um pano de fundo sob o qual as artes (e as artes dos povos indígenas) passam a integrar os currículos de ensino médio. Foi a Lei de Diretrizes e Bases da Educação Nacional, de 1971, que incluiu a Arte no currículo escolar, porém não como disciplina, mas como atividade educativa, expressa por meio do nome de Educação Artística. Em 1996, a Lei n. 9.394 - Lei de Diretrizes e Bases da Educação Nacional - torna a arte um componente curricular obrigatório, respeitando as quatro habilitações da área: Música, Teatro, Dança e Artes Visuais (BRASIL, 1996).

No ano 2008 foi instituída a Lei n. 11.769 que trata da obrigatoriedade do ensino da Música nas escolas de educação básica. A Lei estabelece que a música deve ser trabalhada em todos os níveis e não há exigência de formação específica para a docência. A dança se torna obrigatória por meio da Lei n. 13.278, editada em 2016 (que altera o § $6^{\circ}$ do Art. 26 da Lei n. 9.394, Lei de Diretrizes e Bases da Educação) (BRASIL, 2016).

0 ensino de Arte, conforme as diretrizes curriculares vigentes, deve ser desenvolvido especialmente em suas expressões regionais, de forma a promover o desenvolvimento cultural dos estudantes, e pode-se dizer que há uma importante valorização das diferenças culturais nessas normativas. Da mesma forma, os ensinos da história e da cultura afrobrasileira e indígena também passam a ser considerados conteúdos obrigatórios e, como afirmamos anteriormente, essa inclusão foi também fruto de mobilizações de professores indígenas, organizadas nos Estados de Mato Grosso, Mato Grosso do Sul, Rondônia, Roraima e Acre no final da década de 1980 e nos anos iniciais da década seguinte, cuja demanda principal era a autonomia de suas escolas, mas também reivindicavam que "nas escolas dos não-índios, será corretamente tratada e veiculada a história e cultura dos povos indígenas brasileiros, a fim de acabar com os preconceitos e racismo." (GRUPIONI, 1992, p. 483).

Conforme a Lei de Diretrizes e Bases da Educação Nacional, a Arte no ensino médio está inserida na área chamada de "Linguagens e suas tecnologias" (outras disciplinas também compõem essa área do conhecimento, que são Língua Portuguesa, Literatura, Língua Materna para Populações Indígenas, Língua Estrangeira Moderna e Educação Física). A Arte deve ser trabalhada, conforme o referido texto legal, em suas expressões cênicas, plásticas teatrais e musicais. As chamadas linguagens da Arte são reforçadas nos Parâmetros Curriculares Nacionais, que sustentam que tal ensino deve contemplar Música, Teatro, Dança e Artes Visuais no ensino fundamental e as mesmas habilitações para o ensino médio, com a inclusão, ainda, do audiovisual. 
Os Parâmetros Curriculares Nacionais afirmam, ainda, que frequentemente a Arte é posicionada à margem, nos currículos, frente a outras disciplinas que são consideradas mais importantes. Avalia-se, assim, que o componente curricular tem sido visto como menos importante em razão do desconhecimento, em termos pedagógicos, do potencial da imagem, do som, do movimento e da percepção estética como fontes de conhecimento. Nos termos do referido documento,

\begin{abstract}
observando a nossa história de ensino e aprendizagem de Arte na Escola Média, nota-se um certo descaso de muitos educadores e organizadores escolares, principalmente no que se refere à compreensão da Arte como um conhecimento humano sensivel-cognitivo, voltado para um fazer e apreciar artísticos e estéticos e para uma reflexão sobre sua história e contextos na sociedade humana. Isso tem interferido na presença, com qualidade, da disciplina Arte no mesmo patamar de igualdade com as demais disciplinas da educação escolar. (BRASIL, 2000, p. 46).
\end{abstract}

Vale ressaltar que o documento mencionado promove não apenas uma crítica ao modo de abordagem de arte nas escolas, mas também uma abertura para o sentido sociocultural dessa abordagem, que parece ter favorecido a valorização de várias expressões e formas de arte e, nesse sentido, também as artes dos povos indígenas, embora não mencionadas literalmente.

Por fim, as discussões acerca da Base Nacional Comum Curricular (BNCC) também impactam o componente curricular Arte. A BNCC é um documento de caráter normativo que deverá nortear os currículos e os Projetos Político-Pedagógicos das escolas, e já está disponivel e aprovada a Base para a educação infantil e para o ensino fundamental (BRASIL, 2018). No que concerne ao ensino médio, está disponível apenas um documento norteador, já sistematizado pelo Conselho Nacional de Educação (BRASIL, 2018), mas o texto final não estava, até a data de produção deste artigo, aprovado em sua forma definitiva pelo Conselho Nacional de Educação. Quando aprovado, será obrigatório e norteará os currículos das escolas desse nível de ensino. No primeiro ano letivo subsequente à data da publicação os sistemas de ensino deverão estabelecer um cronograma, iniciando o processo de implementação, que ocorrerá a partir do segundo ano letivo.

No documento preliminar do ensino médio, disponível para consulta e discussão, elencam-se inicialmente problemas que comprometem a qualidade da educação oferecida. Identifica-se, por exemplo, como problemática, a organização curricular, atualmente dividida em componentes curriculares em excesso, além de uma abordagem pedagógica distante das culturas juvenis e do mercado de trabalho. 
0 componente curricular Arte está integrado à área de Linguagem e suas tecnologias e tem foco "na apreciação e na participação em diversas manifestações artísticas e culturais e no uso criativo das mídias." (BRASIL, 2018, p. 417). Investe-se em um sentido de arte como componente curricular que possibilita "o desenvolvimento da autonomia criativa e expressiva dos estudantes, por meio da conexão entre racionalidade, sensibilidade, intuição e ludicidade." (BRASIL, 2018, p. 475). Nessa direção, afirma-se também que, com a aprendizagem em Arte

as percepções e compreensões do mundo se ampliam no âmbito da sensibilidade e se interconectam, em uma perspectiva poética em relação à vida, que permite aos sujeitos estar abertos às percepções e experiências, mediante a capacidade de imaginar e ressignificar os cotidianos e rotinas. (BRASIL, 2018, p. 475).

As linguagens da Arte também são respaldadas, pois contemplariam aspectos corporais, gestuais, teatrais, visuais, espaciais e sonoros na formação dos estudantes. Estimula-se a organização sistemática de práticas que suscitem a criatividade, bem como de planejamentos interdisciplinares capazes de "incorporar estudo, pesquisa e referências estéticas, poéticas, sociais, culturais e políticas, para criar novas relações entre sujeitos e seus modos de olhar para si e para o mundo." (BRASIL, 2018, p. 475).

Outro aspecto importante, destacado na BNCC para o ensino de Arte no ensino médio é a abordagem das diferentes manifestações culturais populares, presentes no contexto de vida dos estudantes. Sugere-se que o ambiente de aprendizagem não se restrinja ao escolar, mas incorpore museus, centros culturais e espaços de práticas artísticas, musicais, teatrais do entorno da escola. Indaga-se, no entanto, se a visitação a esses "outros" espaços de arte são suficientes para a problematização de parâmetros de validação das práticas artísticas e para a revisão de pressupostos eurocêntricos que servem de referência para definir o que está incluído ou excluído do que chamamos de arte. Passamos, a seguir, à análise de expressões das artes dos povos indígenas nos dois livros didáticos selecionados para o presente estudo, buscando problematizar alguns sentidos cristalizados e reproduzidos em discursos didáticos da atualidade. 


\section{SENSO ESTÉTICO, PRÁTICO, FUNCIONAL...: PROBLEMATIZANDO DISCURSOS SOBRE ARTES INDÍGENAS BRASILEIRAS}

Para a análise que se pretende realizar, é relevante discutir - ainda que brevemente - o que vem sendo chamado de arte indígena brasileira, com amparo em teorizações procedidas de antropólogos como Vidal (1992), Lagrou (2009) e Ribeiro (1983).

Há grande diversidade de expressões e formas de se manifestar artisticamente entre os indígenas que habitam o território brasileiro. Sobre isso, estudos da arte dos povos indígenas buscam entender o significado e a relevância desta para os membros de uma dada coletividade, dentro do contexto mais amplo que lhe constitui e dá sentido (VELTHEN, 2003). Nessa perspectiva, arte indígena comporia, junto a outras expressões de uma coletividade, aquilo que constitui sua cultura. Assim, é dentro dos quadros referenciais de cada cultura que um objeto (artístico) adquire lugar e relevância singular.

Vale ressaltar que o esforço em nomear e classificar as artes dos povos indígenas deriva de uma necessidade e preocupação de nossa cultura (ocidental, moderna) e de nosso anseio por imprimir ordem. Os povos indígenas não investem em uma definição de arte, ou num enquadramento de suas produções dentro de critérios da arte ocidental, eles não precisam disso para embasar ou validar suas formas de arte. Como salienta Nunes (2011, p. 146), "somos nós que, por alguma razão, precisamos incluir seus artefatos, canções, danças e pintura corporal, com seu alto grau de elaboração formal e seus significados culturais específicos, no nosso universo artístico." É preciso reconhecer que os sentidos de arte são variáveis (em diferentes contextos, tempos, culturas) e que entre os povos indígenas os sentidos atribuidos aos objetos que denominamos artísticos são distintos daqueles que reconhecemos na atualidade como "verdadeiros". Aliás, a classificação de elementos em campos disciplinares é uma invenção moderna e ocidental (e, portanto, contextual e localizada), e não a expressão de categorias de validade universal.

Conforme Lagrou (2009, p. 11), os povos indígenas "são povos que não partilham da nossa arte." Para a autora, a arte ocidental se distingue das artes indígenas por se destinar, principalmente, à contemplação estética. Entretanto, o próprio conceito de estética é ambivalente na cultura ocidental e se modifica constantemente. Em se tratando de objetos elaborados pelos indígenas, conforme Ribeiro (1983), normalmente são entendidos como tendo fins utilitários, mas de igual forma são expressões com fins estéticos (dimensões que, na vida indígena, não se separam). 0 autor prossegue argumentando que 
assim é porque a característica distintiva da arte é ser mais um modo do que uma coisa, mais forma do que conteúdo, mais expressão do que entidade. Suas criações se apresentam como um conjunto estilizado de modos de fazer certas coisas, de contar uns casos, de cantar e de dançar. 0 que caracteriza a arte índia, entre as artes, é este modo generalizado de fazer todas as coisas com uma preocupação primacialmente estética. (RIBEIRO, 1983, p. 30).

Esse autor explica, ainda, que a confecção de objetos de uso, pelos indígenas, tem alto grau de atenção e de busca da perfeição - "certas criações conformadas pelos índios de acordo com padrões prescritos, geralmente para servir a usos práticos, mas buscando alcançar a perfeição" (RIBEIRO, 1983, p. 29) - o que significaria uma associação entre a função efetiva na vida cotidiana e a função estética dos objetos.

Como argumenta Nunes (2011), Arte não seria, assim, um campo particular, mas expressão que perpassa a produção material de uma coletividade, e teria, ao mesmo tempo, funções estéticas e práticas.

\footnotetext{
Em qualquer livro de história da arte brasileira, encontraremos um capitulo dedicado à "arte indigena". Mas a consideração de certos objetos produzidos por culturas que não possuem o conceito de "arte" da mesma forma como nós o entendemos, como "arte", apresenta variados problemas. Para nós, "arte" (no sentido mais tradicional) é uma atividade ligada à produção de um certo tipo de objetos que têm como principal função a de serem contemplados; esta contemplação ocorre, preferencialmente, em locais separados e específicos, distantes das interferências do mundo cotidiano. 0 museu e a galeria são ambientes limpos, silenciosos, onde as obras de arte podem ser apreciadas da forma que se considera a mais adequada à sua função maior, que é a contemplação estética. Quando falamos de "arte indigena", porém - ou de "artes indigenas", termo mais adequado por atentar para a imensa variedade de estilos e manifestações que cabem na definição $\square$, as coisas são completamente outras. Isso porque, se a considerarmos em relação ao seu "habitat" natural, os objetos das assim chamadas "artes indigenas" não "funcionam" da mesma forma que a arte com que estamos hoje acostumados, ou seja, a arte ocidental, que nasce a partir da experiência europeia. (NUNES, 2011, p. 143).
}

Também parece relevante destacar que, conforme Lagrou (2009), em culturas nas quais não há distinção entre objetos para serem contemplados e outros para serem utilizados, possivelmente não se investe na construção de um conhecimento específico (uma "teoria da arte" em sentido estrito, capaz de circunscrever um "mundo da arte"). Entretanto, distintas coletividades possivelmente elaboram outros tipos de diferenciação e de classificação dos objetos, edificando, assim, cadeias de sentido que definem o que é relevante e o que merece atenção por parte dos membros daquela etnia ou grupo de pertença. 
É possível afirmar, ainda, que a inserção de artefatos indígenas no rol daquilo que classificamos como objetos de arte pode estar vinculada a uma tentativa de conferir valor positivo a produções indígenas (e, nesse caso, o enquadramento atestaria a sua qualidade estética). Contudo, frequentemente os objetos indígenas passam a ser vistos como artísticos depois que são integrados aos nossos modelos de exposição de arte - em museus, em galerias, em exposições, instalações, etc. Por isso, Nunes (2011, p. 144) argumenta que "considerar as artes indígenas como 'arte' sem maiores problematizações é um reducionismo simplista, que esconde uma forma de colonização e domínio benevolente."

Com base nos argumentos apresentados, afirmamos que a incorporação de um capítulo ou seção sobre arte indígena em um livro didático de Arte pode, por um lado, colaborar para tornar visíveis expressões estéticas variadas e, por outro lado, incorrer em simplificações e generalizações, ou em enquadramentos de base eurocêntrica, que não contribuem para uma formação crítica dos estudantes, em qualquer nível de ensino.

\section{METODOLOGIA E ANÁLISE DE REPRESENTAÇÕES DAS ARTES DOS POUOS INDÍGENAS NOS LIUROS DIDÁTICOS SELECIONADOS}

A metodologia do presente estudo consistiu em uma análise das representações que focalizou de modo especial as formas de produção, propagação e contestação de certas representações de artes dos povos indígenas. Representação é um conceito central na presente pesquisa e, segundo Hall (1997b), ela se produz na relação entre as coisas, os conceitos e os signos através da linguagem. "0 significado surge, não das coisas em si - a 'realidade' - mas a partir dos jogos da linguagem e dos sistemas de classificação nos quais as coisas são inseridas. 0 que consideramos fatos naturais são, portanto, também fenômenos discursivos." (HALL, 1997a, p. 10).

Há muitas formas de conceber a representação - a reflexiva, para a qual a representação refletiria algo que existe no "mundo real"; a intencional, que focaliza o sujeito autônomo e sua intencionalidade ao representar, e a construcionista, para a qual as formas de nomear e de atribuir sentido constituem as coisas. Hall (1997b, p. 38) adota essa última perspectiva e afirma que "uma vez que nós só podemos ter conhecimento das coisas se elas tiverem sentido, é o discurso - não as coisas por elas mesmas - que produz conhecimento."

Em relação aos procedimentos metodológicos, o exame dos livros didáticos nos conduziu à organização de tabelas para a sistematização das recorrências enunciativas. Nessas tabelas foram reunidos fragmentos de textos e de imagens constantes nas duas 
obras, e, desse procedimento, derivaram duas unidades de análise que são apresentadas e discutidas a seguir. A primeira diz respeito à reiteração ou contestação de representações de base eurocêntrica e a segunda é concernente à incorporação de uma perspectiva multiculturalista, por meio da qual se reforçam alguns discursos naturalizados, mas também se contestam outros, em especial os estereótipos sobre os povos indígenas.

\subsection{REITERAÇÃO OU CONTESTAÇÃO DAS REPRESENTAÇÕES EUROCÊNTRICAS}

Inicialmente ressaltamos que, nos livros didáticos de Arte analisados, as expressões artísticas indígenas estão enquadradas dentro das chamadas "linguagens da Arte", que dizem respeito às artes visuais, às artes cênicas, música e dança, não sendo levadas em consideração as formas como elas são definidas ou classificadas no campo da Antropologia (em modalidades como arte plumária, cerâmica, cestaria, entre outras). São inseridos, nos livros, fragmentos de textos e imagens descontextualizadas, dentro de quadros de pensamento organizados a partir das referidas linguagens da Arte. 0 caráter não fragmentado das práticas indígenas fica subsumido, desse modo, em categorias ocidentais de classificação e de enquadramento, o que também colabora para a permanência da noção de que seriam simples ou pouco expressivas as artes desses povos. Classificar é também uma estratégia de poder e de legitimação do saber.

Uma importante crítica é formulada pelas antropólogas Aracy Lopes da Silva e Lux Vidal (1998): elas afirmam que muitos livros didáticos inserem informações sobre outras culturas e povos, situando-os em uma historiografia de base europeia. Observamos, pois, que de modo geral nas obras didáticas analisadas se constrói uma cronologia baseada em acontecimentos que fazem sentido desde um ponto de vista eurocêntrico, conforme destacamos a seguir.

No livro Por toda Parte há reverências históricas sobre o Brasil e são inseridas duas imagens do "Monumento às Bandeiras", de Victor Brecheret. Tais imagens estão contidas na seção que aborda o tema "Lugares para criar", e que apresenta diversos espaços que são utilizados pelos artistas para a produção de arte. Para exemplificar esse aspecto, o livro destaca o ateliê que foi improvisado para que Brecheret produzisse o monumento já referido, que levou 17 anos para ser concluído. Esse monumento foi inaugurado em 1954 e é constituído por figuras de cavalos e pessoas: representações de portugueses, negros e indígenas (esses últimos trazem cruzes no pescoço e estão puxando uma espécie de barco). 
Essa construção homenageia os colonizadores, representando a "conquista" da terra, feita pelos europeus, com a "ajuda" de indígenas e negros. Para discutir esse aspecto recorremos ao texto de Martins (1999, p. 14), que afirma que o objetivo do monumento às Bandeiras era "destacar a força, o avanço da massa humana aos sertões, às terras desconhecidas", como se não fossem também humanos os que habitavam ancestralmente essas terras. Além disso, as entradas e bandeiras foram expedições financiadas pelo Governo brasileiro, iniciando-se por São Paulo, para capturar indígenas, submetê-los à cultura dos colonizadores e, assim, liberar as terras para empreendimentos de colonização, dizimando coletivos inteiros ou tornando-os mão de obra escrava.

Apesar de o texto do livro não trazer referência explícita aos indígenas, pois o foco são os lugares de criação de obras de arte, a figura de indígenas integra o monumento, colaborando para instituir certos sentidos e certos lugares sociais para esses sujeitos. Aliás, a figura indígena aparece de forma imponente, no referido monumento, o que poderia ser visto como elemento positivo, mas é posicionada como aquele que aderiu ao projeto colonial, que foi cristianizado e que contribui para a propagação de um modelo de integração e desenvolvimento nacional. Nesse contexto, a figura indígena no monumento le na fotografia do livro didático) colabora para estabelecer um sentido de conquista, supostamente forjada com o aval e a colaboração dos índios. Sobre a construção dos monumentos ligados aos bandeirantes, Martins (1999, p. ११-१२) afirma:

\footnotetext{
Vetor e produto da ascensão dos paulistas republicanos, a construção mítica do bandeirante emergiu desde fins do século XIX, numa representação heróica que se prestava a legitimar historicamente a pujança das elites paulistas ligadas aos negócios da cafeicultura e ao governo da própria República, e que estivera unida de alguma forma aos momentos-chave da nação como início da colonização ou a própria aclamação ao grito do lpiranga.
}

Pode-se dizer que a ação heroica dos paulistanos e colonizadores contrasta com a dos indígenas e africanos, incluídos nessas representações em uma condição servil. Grupioni (1992, p. 490) também salienta que, no período da colonização, a figura do índio aparece ligada à do bandeirante, "que expande o território e resolve o problema da mão-deobra, escravizando índios e depois recapturando negros fugidos."

Dito isso, vale ressaltar que uma das poucas ocorrências da palavra "indígena" no livro Por toda Parte posiciona esses povos a partir de seu passado, e está vinculada à catequização, conforme o trecho a seguir: "No Brasil, o teatro teve início na época da colonização, organizado pelos padres jesuítas. Eles usavam as encenações para catequizar os indígenas. Nelas misturavam aspectos da vida local com o evangelho e a vida dos santos." (FERRARI et al., 2013, p. 226). A inserção desse fragmento ocorre no contexto de discussão dos antecedentes históricos das artes cênicas. Conforme Aguiar (2011), nos processos de 
catequização e cristianização, feitos nos primeiros anos da colonização brasileira, os padres missionários projetavam um modelo que consideravam adequado para inserir e assim modificar os modos de ser e de pensar dos indígenas. E para que ocorressem essas mudanças, os corpos indígenas eram submetidos a técnicas de correção e exercícios constantes. Dessa forma, "tem-se então, uma ação que visa transformar e conduzir a potência de vida para uma condição de produtividade orientada não pelo desejo e necessidade do sujeito, mas pelo desejo do outro, do de fora." (AGUIAR, 2011, p. 92). Ainda sobre essa forma de representar os indígenas, vinculando-os aos processos de catequização, Bonin (2007) afirma que alguns textos teatrais utilizados pelos jesuítas operavam a demonização das crenças indígenas.

Nestes autos o mau era representado por animais que, em geral, tinham sentido xamânico para os povos indigenas (cobra-grande, urubu-rei, onça, tamanduá). Assumindo a forma desses animais o mal se espalharia pela mata, penetrando a alma dos homens em rituais de transe e festas pagãs. Em muitos desses textos figuravam nomes importantes da cosmologia indígena e líderes de movimentos de resistência à colonização, descritos ali como partícipes do reino de Satanás. (BONIN, 2007, p. 92).

A referência histórica da origem do Teatro, no livro didático, vincula-se, assim, a um esforço por combater e transformar as práticas dos povos indígenas, que não seriam, portanto, tidas como adequadas ou valorosas. É interessante observar, em relação ao recorte apresentado no livro, que os sujeitos da ação são os jesuítas e não os indígenas - estes seriam objetos da ação missionária, o que reafirma o sentido de passividade historicamente engendrado, em representações sobre esses sujeitos.

Já no livro Arte em Interação apresenta-se um box, no segundo capítulo, dedicado à América Pré-Colombiana. 0 texto inicia da seguinte forma:

\footnotetext{
Apesar de estudarmos a história de nosso país somente após a chegada dos portugueses, sabemos que muitos povos viviam no Brasil muito antes de isso acontecer. 0 fato de que não possuíam linguagem escrita dificulta os relatos históricos, mas resquícios materiais de descobertas arqueológicas nos dão muitas pistas da ocupação do território brasileiro, antes de 1500, e de hábitos e costumes de vários povos que aqui viviam. (BOZZANO; RRENDA; GUSMÃo, 2013, p. 60).
}

Desse recorte, gostaríamos de salientar, em primeiro lugar, o reconhecimento de que o evento inicial - na cronologia histórica que se registra deste país - é a chegada dos portugueses. Trata-se da legitimação de um olhar eurocêntrico que dá forma ao que é representado, e que, embora reconheça a existência dos indígenas no território antes da chegada das caravelas portuguesas, não reconhece a legitimidade da ocupação indígena 
(afinal, não se poderia "descobrir" uma terra cuja presença humana se considera legítima, só se poderia invadi-la ou conquistá-la com uso da força). 0 uso da preposição "pré", seguida do nome do suposto descobridor é um traço visível dessa base cronológica fundamentada em eventos que fizeram (e fazem) sentido desde uma mirada eurocêntrica.

Do recorte anterior desejamos discutir, ainda, uma forma de representação que tem sido recorrente em relação aos povos indígenas (e às diferenças em geral), qual seja, a da "falta de algo" ou da incompletude. 0 argumento contido no texto didático - "não possuíam linguagem escrita" - é exemplar nesse sentido. A escrita é, para o mundo ocidental moderno, um traço icônico e, ao marcar o outro com a falta dessa tecnologia, marca-se uma suposta carência que funciona para limitar suas possibilidades de criação e manutenção das culturas, artes, ciências, etc. Sobre a vinculação entre a retórica da falta e a perspectiva eurocêntrica, Shohat e Stam (2006, p. 22-23) explicam:

Ao fazer o relato dos acontecimentos, o discurso eurocêntrico purifica a história ocidental ao passo que trata com condescendência, ou mesmo com horror, o não ocidental. Ele pensa sobre si mesmo com base em suas conquistas mais nobres - a ciência, o progresso, o humanismo - e sobre o não ocidental com base em suas deficiências, reais ou imaginárias.

A representação da "falta" (no recorte do livro didático apresentado anteriormente) é seguida da afirmação de que "resquícios materiais" serviriam para entender a forma de ocupação, os hábitos e os costumes indígenas. Essas afirmações, além de representarem os povos indígenas por supostas carências (de linguagem escrita, nesse caso), reforçam a ideia de que são culturas do passado, das quais apenas existem ruínas, resquícios materiais, restos de algo que passou. No recorte a seguir, extraído do mesmo texto do livro Arte em Interação, também se estabelece essa representação: "Na ilha do Marajó foram encontrados vestígios de uma rica cultura que ocupou a região entre 400 e 1400." (BOZZANO; FRENDA; GUSMÃO, 2013, p. 60).

Sobre essa vinculação entre as culturas tradicionais e os vestígios históricos, Bonin e Gomes (2008, p. 10) indagam: "quais significados são produzidos quando fazemos referências a uma civilização, destacando suas 'ruínas'?" Ao que parece, o termo ruína é bom para pensarmos nas "ricas civilizações" que viveram (e vivem) nessas terras, mas ele colabora para o apagamento da atualidade dessas ricas culturas, que efetivamente vivem, no presente. Além do mais, o termo "ruína" parece servir como parâmetro para se estabelecerem comparações entre a cultura material de um povo e outro - como se esse fosse um critério confiável e verdadeiro, por meio do qual se comprovaria a complexidade do pensamento de uns (europeus) em relação à simplicidade dos outros (ameríndios). 
Contudo, nos livros em análise, há tentativas de deslocamento de uma visão pretérita da presença indígena. Nesse sentido, na obra Por toda Parte sugere-se que os estudantes construam conhecimentos, com a seguinte proposição: "Pesquise se próximo de onde você mora existe alguma comunidade indígena e como sua população vive e desenvolve sua cultura." (FERRARI et al., 2013, p. 158). Também no livro Arte em interação, um box intitulado "Foco na prática" propõe que os estudantes organizem grupos e busquem conhecer "as manifestações artísticas atuais" dos povos indígenas, o que parece indicar uma preocupação em contextualizar e, ao mesmo tempo, conferir atualidade à presença indígena, levando em conta as localidades e especificidades regionais. Trazemos a seguir um fragmento desse texto:

\begin{abstract}
Para conhecer melhor a cultura dos povos indigenas do Brasil, você fará uma pesquisa em grupo sobre suas manifestaç̃̃es artísticas atuais. Cada grupo será responsável por pesquisar uma nação indígena diferente. [...] Para a pesquisa, considerem questões como: quais as manifestações artísticas atuais dos povos escolhidos? A que tradições e costumes estão relacionadas? 0 que ainda há de similar e o que mudou nas manifestações ancestrais dessas culturas, e por que isso ocorreu? (BOZZANO; FRENDA; GUSMÃ0, 2013, p. 60).
\end{abstract}

Quando Bonin e Gomes (2008) examinaram livros didáticos de história, observaram que a maior parte das referências aos indígenas está concentrada nos primeiros séculos da colonização e que há poucas ocorrências no período correspondente ao "mundo contemporâneo". E eles examinam mais detidamente uma fotografia inserida em uma das obras (a única que se localizava no "período contemporâneo", conforme classificação do livro didático). A fotografia é acompanhada de um texto verbal que sugere que muitos povos indígenas teriam sido destruídos e suas culturas teriam sido alteradas pela imposição colonial. Na fotografia, da década de 1990, apresenta-se um grupo de homens do povo Kaiapó, organizados em semicírculo. "Eles têm seus corpos pintados de preto, cocares na cabeça, lanças nas mãos, vestem calções vermelhos e calçam sandálias de borracha." (BONIN; GOMES, 2008 , p. 11). Os autores prosseguem afirmando que a fotografia permite ver, ao fundo, as casas tradicionais dos Kaiapó, um grupo de mulheres com corpos ornamentados, junto de suas crianças. Na legenda da fotografia apresenta-se a seguinte indagação: “Quais peças da indumentária dos indígenas acima não são, originalmente, de sua própria cultura?" Tomando tal indagação, os autores argumentam:

\footnotetext{
Mesmo quando as imagens indigenas são contemporâneas, elas ilustram um conjunto de informações que fixam os povos indígenas no passado. Além disso, o convite lançado aos estudantes na legenda reafirma um discurso que entende as culturas indígenas como sendo "sempre as mesmas", presas a tradições do passado e, portanto, na medida em que eles transformam suas maneiras de viver e suas práticas, agregando a elas elementos de
} 
outras culturas - como, alás, sempre o fizeram - o efeito é avaliarmos esse movimento como sinal de "perda cultural". (BONNN; GOMES, 2008, p. 11-12).

Recuperamos, então, do recorte do livro Arte em Interação, anteriormente apresentado. A indagação é "O que ainda há de similar e o que mudou nas manifestações ancestrais dessas culturas?" Pode-se dizer que também se constrói uma representação das culturas indígenas como estáticas, como se devessem corresponder a uma suposta cultura original, autêntica, verdadeira, ancestral. A palavra "ainda", utilizada na indagação, remete à noção de que há uma gradativa perda dessa "originalidade", e leva a pensar que aquilo que não se "perdeu", gradativamente será "perdido". Contudo, cultura não é substância, como afirma Canclini (2007, p. 41), "cultura abarca o conjunto dos processos sociais de significação", sendo que as significações mudam em qualquer grupo social. Por isso, o autor afirma que a cultura deveria ser pensada mais como processo do que como produto lou seja, cultura não é "coisa" que se ganha ou perde). Sob essa conceituação, a noção de cultura como acúmulo de conhecimentos e experiências perde a centralidade. A cultura passa a ser pensada como processual, e, portanto, dinâmica e aberta a mudanças, reformulações, contestações, hibridações, etc. 0 autor afirma a importância de se estudarem, nas sociedades contemporâneas, a recepção e a apropriação de bens e mensagens, bem como a forma como os objetos adquirem novos significados em relações interculturais, para evitarmos as armadilhas de pensar cultura como algo fixo, natural, dado, essencial, original, puro. 0 exemplo apresentado pelo autor é sugestivo:

Os objetos artesanais costumam produzir-se em grupos indigenas ou camponeses, circulam por distintas sociedades e são apropriados por setores urbanos, turistas, brancos, não-indigenas, com outros perfis socioculturais, que thes atribuem funções distintas daquelas para as quais se fabricam. (CANCLINI, 2007, p. 42).

No trânsito, tais objetos adquirem distintas significações - que não correspondem àquelas que lhes atribui o artesão que os fabrica, ou a etnia da qual é procedente. Os objetos artesanais, por sua vez, adquirem significados distintos se forem incorporados à decoração de uma residência ou se forem incluídos em coleções museológicas. Podem ser presenteados, doados, comercializados, e isso também configura seus sentidos para aqueles que os adquirem. De modo análogo, pode-se dizer que os acontecimentos que envolvem uma comunidade, um povo, uma nação também são entendidos de maneiras muito variáveis, dependendo do lugar em que são narrados, registrados, reelaborados, dos sujeitos envolvidos e das relações de poder que permeiam todo esse processo. Assim, entende-se que os sentidos são construídos e, ainda mais, são disputados por diferentes segmentos sociais, em um mesmo tempo e espaço. Os livros didáticos participam nessas lutas por 
imprimirem certos sentidos e por legitimarem certas maneiras de pensar a arte (em geral) e as artes dos povos indígenas (em particular).

Para finalizar essa discussão, argumentamos, com Shohat e Stam (2006) que o eurocentrismo - que vemos reafirmado em trechos dos livros didáticos discutidos neste artigo - é um "resíduo discursivo" de séculos de dominação europeia, que deram forma à uma cultura comum, engendrando um sentimento fictício de superioridade natural dos povos europeus (aos que a ele aderiram). Para os autores (SHOHAT; STAM, 2006, p. 21):

\footnotetext{
0 eurocentrismo bifurca o mundo em "Ocidente e o resto" e organiza a linguagem do dia-a-dia em hierarquias binárias que implicitamente favorecem a Europa: nossas nações, as tribos deles, nossas religiões, as superstições deles, nossa cultura, o folclore deles, nossa arte, o artesanato deles, nossas manifestações, os tumultos deles, nossa defesa, o terrorismo deles.
}

Nos livros didáticos de arte analisados, uma perspectiva eurocêntrica continua a posicionar a Europa como centro da narrativa sobre arte, e essa forma de pensar colabora para definir o lugar da arte indígena como uma "arte outra". Nos dois livros, os eventos selecionados para compor os capítulos são, em grande medida, sustentados em uma visão eurocêntrica da história da arte. Assim, mesmo promovendo a inclusão das artes dos povos indígenas, ainda se reitera um pensamento binário a respeito do "o ocidente/o resto". Passamos, na seção seguinte, a discutir as representações multiculturalistas e as contestações feitas a uma noção genérica de índio, nos livros didáticos de Arte.

\subsection{PERSPECTIUA MULTICULTURALISTA, APELO AO DIUERSO E CAPTURA DAS ARTES DOS OUTROS}

Examinando os dois livros didáticos articuladamente, um aspecto que se sobressai é a abordagem da arte indígena como uma "arte outra", mas nesta seção destacamos que essa outridade é trazida como parte integrante da "diversidade cultural" a ser valorizada. E o apelo à diversidade se expressa de forma direta ou indireta, por meio do discurso multiculturalista.

A perspectiva multiculturalista pode ser vista como parte de uma engrenagem a partir da qual se governam ou administram problemas gerados em sociedades multiculturais. Conforme Hall (2008), o multiculturalismo afirma a diversidade e a pluralidade humanas por meio de um apelo à tolerância. Entretanto, muitas vezes naturaliza as diferenças, o que dificulta as lutas específicas de grupos desfavorecidos, pois desconsidera as relações de poder implicadas na classificação do lugar social de cada um. Desconsidera, ainda, a tensão existente entre o 
reconhecimento da diferença e a realização da igualdade. 0 "outro" cultural seria, assim, um problema a ser administrado, uma vez que sua presença põe em xeque a própria identidade lou a supremacia das práticas culturais e artísticas selecionadas como válidas).

Os estudos culturais têm problematizado as perspectivas multiculturalistas, a partir das quais se celebra uma suposta diversidade constituinte de nossa "natureza" humana. Esses estudos recolocam a perspectiva da diferença - conceito que leva a pensar nos processos de produção, classificação, hierarquização das culturas, e nas relações de poder que definem quem seriam os diferentes. No espaço acadêmico, são muitas as discussões sobre o multiculturalismo e estas têm mobilizado pesquisadores filiados a diferentes perspectivas teóricas.

Em um dos livros analisados, um sentido de unidade, por meio da mescla de diferentes matrizes na formação cultural brasileira, explicita-se no seguinte recorte:

No Brasil, há uma mistura de várias culturas com identidades diferentes. Com o processo de colonização, buscou-se impor a arte e a cultura de origem europeia. Isso não impediu a manutenção de outras culturas ancestrais, como a indigena e a africana, que estão enraizadas em nossa formação cultural. (BOZZANO; FRENDA; GUSMÃO, 2013, p. 58).

Apesar de os autores iniciarem criticando a imposição da cultura e da arte europeia, reafirmam a ideia da mistura, noção que reativa uma representação de unidade, formada por partes que se somam e se mesclam formando "uma cultura" nacional. Nesse sentido, as culturas dos outros povos são vistas como unidades menores, subjugadas a uma totalidade maior. A submissão das culturas indígenas e afro-brasileiras a uma cultura modelar ocorre a partir de sua qualificação como "ancestrais" e "enraizadas em nossa formação cultural". Desse modo, cultura e arte indígena se convertem em "raízes" ancestrais, o que pode impossibilitar pensar nelas como expressões atuais, recriadas pelos povos indígenas que compõem nosso País, sem necessária vinculação a uma cultura comum. Hall (2008) afirma que a invenção dessa totalidade - correspondente a uma identidade nacional - acontece por diferentes estratégias, e seria constituidora de uma ideia de nação miscigenada.

0 uso da noção de miscigenação parece ser comum em discursos multiculturalistas que, desse modo, tornam visível a diversidade, mas também mantêm assimetrias culturais. As culturas indígenas figuram como matrizes na formação da sociedade brasileira em diversas produções contemporâneas, e são fortemente marcadas como parte de um passado comum - e não de um presente comum.

Em um dos livros didáticos há um box chamado América Pré-Colombiana, que informa que a cerâmica seria utilizada muito antes da chegada dos portugueses, pelos 
povos indígenas, e teria sido transmitida de geração em geração, "na mistura entre povos que ocuparam o Brasil." (BOZZANO; FRENDA; GUSMÃ0, 2013, p. 60). Naturaliza-se, também nesse livro didático, a representação do povo brasileiro originado na "mistura" entre distintas etnias, por atributos culturais de diferentes matrizes justapostas, algo que, conforme afirma Bernd (1992, p. 14), "circunscreve a realidade a um único quadro de referências." A construção de uma identidade brasileira se dá na literatura (e também na literatura didática) inicialmente por mecanismos de exclusão (que a autora caracteriza como a ocultação ou invenção do outro) e de transgressão (caracterizada por ações como o resgate dos discursos dos excluídos). A autora lembra que as identidades, tanto quanto as diferenças, precisam ser narradas: "uma coletividade ou um indivíduo se definiria, portanto, através das histórias que ela narra a si mesma sobre si mesma e, dessas narrativas, poder-se-ia extrair a própria essência da sua definição." (BERND, 1992, p. 17).

A ideia de diversidade ganha expressão em muitos materiais que vemos circular nas escolas hoje, assim como em manuais, em diretrizes curriculares, em pronunciamentos de especialistas da Educação, em produções didáticas, entre outras. Muitos discursos em prol da diversidade não permitem a crítica sobre as condições a partir das quais se define quem seria diferente e também não problematizam as assimetrias nas relações entre os indígenas e a sociedade envolvente. Nesse sentido, Bauman (2003) afirma que o multiculturalismo promove uma naturalização de aspectos que são disputados no âmbito da cultura. Sob a rubrica da igualdade, muitas vezes se desconsideram as condições particulares implicadas nas desiguais formas de distribuição dos recursos. Em tal perspectiva, existiriam formas presumivelmente naturais de ser e, dada a diversidade das sociedades, teríamos que aprender a conviver e a tolerar as distintas maneiras de ser, de pensar e de viver. Para o referido autor, o sucesso dos discursos multiculturalistas se deve ao desengajamento (produzido em uma racionalidade neoliberal) e ao excesso (de ofertas, de mercadorias, de imagens, de mensagens) que nos transformam em sujeitos de escolhas - consumidores de serviços - e não em sujeitos de direitos.

Na perspectiva dos estudos culturais existem múltiplas culturas, o que indica haver disputas acerca de significados e distintos investimentos na produção de identidades. Não se trata apenas de diferentes práticas culturais ligadas a distintas etnias, mas de culturas marcadas por diferentes pertencimentos - culturas surdas, culturas juvenis, culturas infantis, culturas laborais, entre outras. Mais uma vez, insistimos que as diferenças são constituídas no âmbito da cultura e estabelecidas em relações de poder, e assim devem ser abordadas, com todas as tensões que decorrem dessa abordagem.

Alguns estereótipos se mantêm, nos livros analisados nesse texto, construindo significados para os povos indígenas, mas também há um esforço em problematizar representações que empobrecem e desqualificam as culturas indígenas. No livro Arte em Interação contesta-se e desloca-se a visão genérica de índio em trechos como: "Mas apesar 
dessa forte presença, muitos brasileiros desconhecem essas culturas, ou as veem somente de um jeito estereotipado." (BOZZANO; FRENDA; GUSMÃ0, 2013, p. 58). Em outro recorte se afirma que:

\begin{abstract}
[..] uma visão europeia, a visão dos colonizadores, de mundo e da sociedade, fezse dominante, o que faz com que, ainda hoje, haja um grande desconhecimento dessas culturas ancestrais das quais somos herdeiros. As culturas indigenas no Brasil, por mais que se encontrem dentro do território em que vivemos, ainda são vistas por muitas pessoas com olhar estereotipado e equivocado. De um modo geral, não se conhecem seus modos de vida, visão de mundo, as semelhanças e diferenças entre seus povos. Há, inclusive, uma tendência de se entender os indigenas todos da mesma maneira. Diz-se o "indio", no singular, sem diferenciar as centenas de povos indigenas que vivem no território brasileiro. (BOZZANO; RRENDA; GUSMÃO, 2013, p. 59).
\end{abstract}

Na sequência do livro didático, explicam-se os contextos de uso dos termos "índio" e "indígena", relacionando-os com outros termos como "autóctone" e "nativo". Várias estratégias vão sendo utilizadas para pluralizar o sentido do termo "indígena". Uma delas é a inserção de dados estatísticos que permitem entender quantos são, quantas etnias existem e quantas línguas são faladas. No box "Cápsulas", inserido na mesma página do livro, apresentam-se dados extraídos de sites de organizações não governamentais e dados do IBGE sobre a presença indígena no País.

Uma outra estratégia utilizada para deslocar e contestar o sentido genérico do termo "índio", nos livros analisados, é a inserção de exemplos relativos às práticas culturais dos povos indígenas. Destacamos, aqui, os exemplos contextualizados na cultura e arte de um povo indígena específico. Nesse sentido, entre as páginas 60 e 61 (BOZZANO; FRENDA; GUSMÃ0, 2013) são inseridas fotografias do povo Karajá em distintas situações cotidianas. Junto a elas, são colocadas questões para orientar o olhar: " 0 que caracteriza cada uma das imagens? Procure observar os lugares, gestos e posturas [...] Que relações você vê entre elas? Quais elementos possuem em comum? Que materiais você identifica? Quais seus usos e relações entre as imagens?" (BOZZANO; FRENDA; GUSMÃO, 2013, p. 61).

Após esse diálogo direto com o leitor, o texto prossegue explicando que o povo Karajá se autodenomina Iny, que significa "nós", sendo Karajá um nome adotado em Língua Portuguesa, originado do Tupi. 0 texto explica que esse povo vive em seus territórios tradicionais, em uma extensa faixa do Rio Araguaia, na llha do Bananal e que os Karajá estão presentes nos Estados de Tocantins, Goiás e Mato Grosso. Há breves informações sobre os mitos desse povo e sua relação com a arte. São destacados elementos artísticos que o leitor também pode observar nas fotografias - as pinturas corporais, a arte plumária, entre outros elementos. Há informações sobre o processo de produção da cerâmica e das tintas utilizadas para colorir esses objetos e para produzir pinturas corporais. Argumentamos, pois, 
que o texto expressa um sentido mais abrangente de arte, que estaria presente em várias instâncias da vida indígena e discute, inclusive, padrões e abstração em pinturas corporais de povos como os Karajá e os Munduruku, do Alto Tapajós.

0 livro Por toda Parte também faz referência às pinturas corporais dos indígenas. Contudo, não há a intenção de deslocamento do sentido genérico de índio. Na página 157 do referido livro insere-se a fotografia de parte do corpo de um homem, no qual se expõe uma delicada e densa pintura corporal. 0 texto verbal salienta que as pinturas corporais expressam entendimentos sobre a beleza. Essa afirmação é sustentada em uma citação de Ribeiro (1983 apud FERRARI et al., 2013, p. 157): “[...]os indigenas têm uma 'necessidade de beleza' e, por essa razão, criam adornos de plumas, enfeitam seus corpos com pinturas e outros elementos e, assim, criam a arte indígena." Vale ressaltar que adornos corporais, incluindo as pinturas, são distintos entre povos e também entre clãs/famílias/parcialidades de um mesmo povo, e esses aspectos não são mencionados no livro didático. Contudo, embora não haja referência ao sujeito e ao povo ao qual pertence aquela pintura corporal, o livro expande, de certo modo, o sentido, quando afirma que "As concepções de beleza e arte estão relacionadas às particularidades culturais de cada nação ou etnia indígena." (FERRARI et al., 2013, p. 157).

\section{PALAURAS FINAIS}

Finalizamos o presente texto destacando, com Silva e Vidal (1998), que a cultura ocidental cria, muitas vezes, visões estanques das sociedades indígenas, mas a arte para os índios é movimento, dinamismo, expressão de uma experiência coletiva. A análise de artefatos escolares como os livros didáticos é parte de um esforço feito para colocar em movimento visões estanques e para imprimir dinamismo às representações, permitindo que alguns referentes sejam problematizados.

Como permitir que o currículo esteja comprometido com a produção de um pensar que desafie estereótipos e que não esteja capturado pelo pensamento disciplinar? Com Paraíso (2010, p. 589), "podemos dizer que um currículo também não está nunca definitivamente formado. Precisamos, então, rachar os extratos, rachar os currículos existentes em seu meio para ver a diferença fazer o seu trabalho." Assim, parece urgente investirmos em um currículo que se parte le parte os universais, as naturalizações, as certezas, as verdades, os procedimentos padronizados, os programas estabelecidos, os percursos previamente definidos) para permitir que prolifere a diferença. Investir em um currículo permanentemente aberto a novos acréscimos, no qual se possam promover efetivas e produtivas aberturas 
para podermos apreciar as artes dos povos indígenas, com os singulares sentidos que elas podem ter. Um currículo assim, aberto e receptivo, bem pode expandir nossas possibilidades imaginativas e nossas experiências estéticas.

\section{REFERÊNCIAS}

AGUIAR, J. V. S. Narrativas sobre povos indígenas na Amazônia. 2011. 215 f. Tese (Doutorado em Educação) - Faculdade de Educação, Universidade Federal do Rio Grande do Sul, Porto Alegre, 2011.

BAUMAN, Z. Comunidade: a busca por segurança no mundo atual. Rio de Janeiro: Editora Zahar, 2003.

BERND, Z. Literatura e Identidade Nacional. Porto Alegre: Ed. UFRGS, 1992.

BONIN, I. T. E por falar em povos indigenas... quais narrativas contam em práticas pedagógicas? 2007. 220 f. Tese (Doutorado em Educação) - Faculdade de Educação, Universidade Federal do Rio Grande do Sul, Porto Alegre, 2007.

BONIN, I. T. Povos indígenas na rede de temáticas escolares: o que isso ensina sobre identidades, diferenças e diversidade? Currículo sem Fronteiras, v. 10, n. 1, p. 73-83, jan./jun. 2010.

BONIN, I. T.; GOMES, J. C. A. Representações eurocêntricas ensinando sobre gênero e etnia em livros didáticos de história - Ensino Médio. In: SEMINÁRIO DE PESQUISA EM EDUCAÇÃO DA REGIÃO SUL, 7., 2008, Itajaí. Anais [...]. Itajaí: Univali, 2008.

BONIN, I. T.; RIPOLL, D.; AGUIAR, J. V. S. A temática indigena sob as lentes dos Estudos Culturais e Educação - algumas tendências e enfoques analíticos. Educação, Porto Alegre, v. 38, n. 1, p. 59-69, jan./ abr. 2015. Disponivel em http://revistaseletronicas.pucrs.br/ojs/index.php/faced/. Acesso em: 21 jul. 2018.

BOZZANO, H. B.; FRENDA, P.; GUSMÃO, T. C. Arte em interação. São Paulo: IBEP, 2013.

BRASIL. Lei n. 9.394, de 20 de dezembro de 1996. Estabelece as diretrizes e bases da educação nacional. Diário Oficial da União, Brasília, DF, 23 dez. 1996.

BRASIL. Lei n. 11.645, de 10 de março de 2008. Altera a Altera Lei 9.394, de 20 de dezembro de 1996, para incluir no currículo oficial da Rede de Ensino a obrigatoriedade da temática "História e Cultura Afro-Brasileira". Diário Oficial República Federativa do Brasil. Diário Oficial da União, Brasília, DF, 11 mar. 2008.

BRASIL. Lei n. 13.278, de 2 de maio de 2016. Altera o $§ 6^{\circ}$ do art. 26 da Lei. 9.394, de 20 de dezembro de 1996, que fixa as diretrizes e bases da educação nacional, referente ao ensino da arte. Diário Oficial da União, Brasília, DF, 3 maio 2016. 
BRASIL. Ministério da Educação. Base Nacional Comum Curricular - Educação é a base. Documento preliminar - Ensino Médio - homologado pelo Ministério da Educação. Brasilia, DF: MEC, 2018. Disponível em: http://basenacionalcomum.mec.gov.br/wp-content/uploads/2018/12/BNCC_19dez2018_site.pdf. Acesso em: 13 ago. 2018.

BRASIL. Ministério da Educação. Secretaria de Educação Média e Tecnológica. Parâmetros Curriculares Nacionais (Ensino Médio). Brasília, DF: MEC, 2000.

CANCLINI, N. G. A cultura extraviada nas suas definições. In: CANCLINI, N. G. Diferentes, desiguais e desconectados: mapas da interculturalidade. Tradução: Luiz Sérgio Henriques. 2. ed. Rio de Janeiro: Ed. UFRJ, 2007.

COSTA, H. Um olhar que aprisiona o outro: o retrato do índio e o papel do fotojornalismo na revista 0 Cruzeiro. Imagens, Campinas: Ed. Unicamp, n. 2, ago. 1994.

FERRARI. P. et al. Por toda parte: volume único. São Paulo: FTD, 2013.

FUNDO NACIONAL DE DESENVOLVIMENTO DA EDUCAÇÃO. 2015. Disponivel em: http://www.fnde.gov.br/ programas/programas-do-livro/livro-didatico/historico. Acesso em: 6 de dez. 2016.

GRUPIONI, L. D. B. Livros didáticos e fontes de informações sobre as sociedades indígenas no Brasil. GRUPIONI, L. D. B. (org.). Índios no Brasil. São Paulo: Secretaria Municipal da Cultura, 1992.

HALL, S. A Centralidade da Cultura: notas sobre as revoluções culturais do nosso tempo. Educação \& Realidade, Porto Alegre, v. 22, p. 15-46, jul./dez. 1997 a.

HALL, S. A questão multicultural. In: HALL, S. Da diáspora. Identidades e mediações culturais. Belo Horizonte: Ed. UFMG, 2008.

HALL, S. The Work of Representation. In: HALL, S. (org.) Representation. Cultural Representations and Signifying Practices. Sage: Open University; London: Thousand Oaks: New Delhi, $1997 b$.

IBGE. Censo 2010. Disponivel em: https://censo2010.ibge.gov.br/. Acesso em: 21 jul. 2018.

LAGROU, E. Arte indígena no Brasil: agência, alteridade, relação. Belo Horizonte: Editora C/Arte, 2009.

MARTINS, P. C. G. 0 Parque do lbirapuera e a construção da identidade paulista. An. mus. paul., v. 6-7, n. 1, 1999.

MOREIRA, A. F. B.; CANDAU, V. M. Currículo, conhecimento e cultura. In: BEAUCHAMP, J.; PAGEL, S. D.; NASCIMENTO, A. R. (org.). Indagações sobre currículo: currículo, conhecimento e cultura. Brasília, DF: Ministério da Educação, Secretaria de Educação Básica, 2007.

NUNES, F. V. As artes indigenas e a definição de arte. [S. l.: s. n.], 2011. Disponível em: http://www. embap.pr.gov.br/arquivos/File/Forum/anaisvii/143.pdf. Acesso em: 6 dez. 2016. 
OLIVEIRA, T. S. Olhares Poderosos. 2001. Dissertação (Mestrado em Educação) - Faculdade de Educação, Universidade Federal do Rio Grande do Sul, Porto Alegre, 2001.

PAES, M. H. R. Representações cinematográficas "ensinando" sobre o índio brasileiro: selvagem e herói nas tramas do império. 2008. 154 f. Tese (Doutorado em Educação) - Faculdade de Educação, Universidade Federal do Rio Grande do Sul, Porto Alegre, 2008.

PARAíSO, M. A. Diferença no currículo. Cadernos de Pesquisa, v. 40, n. 140, maio/ago. 2010.

RIBEIRO, D. Arte índia. In: ZANINI, W. (org.). História geral da arte no Brasil. São Paulo: Instituto Walther Moreira Salles, 1983. v. 1.

SANTOMÉ, J. T. As Culturas Negadas e Silenciadas no Currículo. In: SILVA, T. T. S. (org.). Alienígenas na sala de aula. 8. ed. Petrópolis: Vozes, 2009.

SHOHAT, E.; STAM, R. Crítica da imagem eurocêntrica. São Paulo: Cosac Naify, 2006.

SILVA, E. Os povos indígenas e o ensino: possibilidades, desafios e impasses a partir da Lei 11.645/2008. In: FERREIRA, G. G.; SILVA, E.; BARBALHO, J. I. S. (org.). Educação e diversidade: um diálogo necessário na Educação Básica. Maceió: EDUFAL, 2015.

SILVA, M. A.; VIDAL, L. 0 sistema de objetos nas sociedades indígenas: Arte e cultura material. In: SILVA, A. L. (org.). A temática indígena na escola. Novos subsídios para professores de $1^{\circ}$ e $2^{\circ}$ graus. Brasília, DF: MEC: MARI: UNESCO, 1998.

SILVA, T. T. Currículo e Identidade Social: Territórios Contestados. In: SILVA, T. T. (org.). Alienígenas na sala de aula. 8. ed. Petrópolis: Vozes, 2009.

VELTHEM, L. H. V. 0 belo é a fera: a estética da produção e da predação entre os Wayana. Lisboa: Museu Nacional de Etnologia: Assírio \& Alvim, 2003.

VIDAL, L. Grafismo indígena: estudos de antropologia estética. São Paulo: Studio Nobel: Ed. USP: FAPESP, 1992.

Endereços para correspondência: Rua Luís Felipe Monmanc, 101, Casa 12, Espirito Santo, 91770-453, Porto Alegre, Rio Grande do Sul, Brasil; m4ri4na@gmail.com 
